\title{
DIETARY REGIMEN AND PERFORMANCE OF HIGH INTENSITY ERGOMETER EXERCISE
}

\author{
J. A. WHITE, S. HARRIDGE, D. STENSIL and A. WYETH \\ Department of Human and Environmental Sciences, West London Institute of Higher Education, Borough Road, Isleworth, Middlesex
}

\begin{abstract}
The influence of preceding diet (mixed, MD; carbohydrate $C D$; protein $P D$ ) on performance during high intensity endurance cycling was examined in six middle distance runners. Subjects undertook cycle ergometer exercise at a workload equivalent to $80 \% \mathrm{VO}_{2}$ max until exhaustion following each of the three dietary regimens. Dietary analyses were performed using a computerised evaluation technique and cardiorespiratory, blood glucose and lactate responses to exercise were measured along with exercise time to exhaustion. Significant differences in carbohydrate and protein intakes were noted between respective diets as well as significantly higher total energy intake in $M D(P<0.05)$. A significant relationship was observed between carbohydrate intake and exercise time to exhaustion $(r=0.59, P<0.05)$. No significant differences were noted in cardiorespiratory measures or blood glucose response after exhaustive exercise between the three dietary regimens but peak blood lactate concentration was lower following PD (P< 0.05). Total time to exhaustion was significantly higher on $C D$ $(1070.0 \pm 106.7 \mathrm{~s})$ than on PD (642.5 $\pm 84.3 \mathrm{~s}, \mathrm{P}<0.01)$. Performance time on MD (895.7 \pm 84.3 s) did not differ significantly for performance time on either CD or PD. It was concluded that dietary manipulation significantly improves exercise time to exhaustion during short term, high intensity cycling.
\end{abstract}

Key words: Diet, Cycle ergometer exercise, Athletes

\section{INTRODUCTION}

The influence of dietary practice on performance has become an important training variable in the general preparation for many athletic events. Since early work demonstrated the importance of dietary carbohydrate in the enhancement of the capacity for prolonged high intensity exercise (Bergström et al, 1967), attention has been directed towards the improvement of exercise performance by dietary manipulation (Coyle and Coggan, 1984; Gollnick and Matoba, 1984). However the importance of dietary carbohydrate in facilitating performance in activities lasting less than forty minutes (Lamb, 1984) to one hour duration (Åstrand and Rodahl, 1986) has been questioned. Moreover, recent studies have attempted to influence performance in very short-term high intensity exercise by varying acid-base status and/or buffer capacity using pre-exercise dietary supplements (e.g. McLaren et al, 1986). The present study was designed to determine the influence of dietary practice upon the performance of relatively short-term high intensity exercise of less than $20 \mathrm{~min}$. duration.

\section{EXPERIMENTAL METHODS}

Six middle-distance runners (4 males and 2 females) who were all final year Sports Studies students were included in the study and the descriptive data of the subjects are outlined in Table I. Prior to the study all subjects were habituated to the experimental procedures involved, especially cycle ergometry, in order to allow accommodation to the specific demands of cycling. The experimental series was conducted over a three-week-period, beginning and ending with the determination of maximal oxygen uptake $\left(\mathrm{VO}_{2} \max \right)$ to ensure that aerobic power remained constant during the intervening period. Furthermore the training regimens of the subjects were held constant during this period. The maximal exercise procedure involved 5 minutes of warm-up exercise at $100 \mathrm{~W}$ and $50 \mathrm{rpm}$ on a

Address for correspondence:

Dr. J. A. White

Division of Sport and Leisure Studies

University of Ulster at Jordanstown

Shore Road

Newtownabbey

County Antrim

Northern Ireland BT37 00B
Monark biycle (Model No. 864), followed by a continuous, incremental protocol. Work rate was increased every 2 mins by $50 \mathrm{~W}$ initially, and then by $25 \mathrm{~W}$ until criteria for attainment of $\mathrm{VO}_{2}$ max were achieved (BASS, 1986).

TABLE I

General characteristics of the subjects in the study $(n=6)$

\begin{tabular}{cccccc}
\hline $\begin{array}{c}\text { Subjects } \\
\text { Male/Female }\end{array}$ & $\begin{array}{c}\text { Age } \\
(\mathrm{yrs})\end{array}$ & $\begin{array}{c}\text { Height } \\
(\mathrm{cm})\end{array}$ & $\begin{array}{c}\text { Weight } \\
(\mathrm{kg})\end{array}$ & $\begin{array}{l}\text { VO }_{2} \text { max } \\
\text { Pre }\end{array}$ & $\begin{array}{c}\text { (I.min } \\
\text { Post }\end{array}$ \\
\hline M & 21 & 171.0 & 63.1 & 4.36 & 4.63 \\
M & 21 & 166.7 & 54.3 & 3.32 & 3.00 \\
M & 20 & 166.7 & 59.4 & 3.68 & 3.42 \\
M & 21 & 176.0 & 64.8 & 3.63 & 3.95 \\
F & 21 & 176.0 & 61.7 & 3.39 & 3.16 \\
F & 20 & 162.0 & 58.4 & 3.07 & 3.03 \\
\hline Mean & 20.7 & 169.7 & 60.3 & 3.58 & 3.53 \\
\pm S.E. & 0.2 & 2.5 & 1.7 & 0.19 & 0.28 \\
\hline
\end{tabular}

During the experimental period subjects undertook three separate cycle ergometer endurance trials to voluntary exhaustion, involving high intensity exercise at $50 \mathrm{rpm}$ at a workload which corresponded to approximately $80 \%$ of $\mathrm{VO}_{2}$ max. Each endurance trial was completed without motivational stimulation or knowledge of time elapsed, with termination point determined by the subject's failure to restore the required pedal rate on the second occasion of dropping below the required $50 \mathrm{rpm}$.

Heart rates were recorded using an automated procedure (Cardiometer, Cardiokinetics). Expired air samples were collected via a low resistance breathing valve (Jakeman and Davies, 1979) in Douglas bags and analysed for oxygen and carbon dioxide using automated Beckman OM11 and LB2 analysers respectively. Capillary blood samples were collected using a finger prick technique and analysed for glucose and lactate (Analox LM2 analyser). All cardio-respiratory measures were taken during the last 30 seconds of each exercise stage in the $\mathrm{VO}_{2}$ max tests, and blood samples obtained before, at $5 \mathrm{~min}$ and upon completion, as well as $5 \mathrm{~min}$ post high intensity exercise during the exhaustive exercise trails.

Prior to each endurance trial subjects were randomly 
assigned to one of three dietary regimens including a mixed (control) diet (MD), a high protein diet (PD) and a high carbohydrate diet (CD). Subjects followed each dietary regimen for three consecutive days before performing each cycle ergometer trial to exhaustion on the fourth day. A period of three days was allowed before each subject was required to follow the next dietary protocol, during which time subjects followed their normal dietary regimen. Subjects recorded all dietary information on a prepared dietary record sheet carefully noting types, weights or volumes of food items consumed during each dietary regimen. All dietary analyses were performed using values derived from standardised food tables (Paul and Southgate, 1979) and a computerised dietary analysis programme ("Microdiet" - Salford University). Individually averaged daily intakes were then calculated for each of the three dietary regimens, from which group average values were derived. Dietary advice was provided to all subjects in an attempt to ensure that total energy intake derived from the three dietary regimens was compatible with minimum recommended daily intakes (DHSS, 1969).

\section{RESULTS}

The dietary analysis representing mean daily nutrient intake for the three dietary regimens is presented in Table II. Whilst significantly greater total energy intake occurred in MD compared with $C D(P<0.05)$, no significant differences were noted in energy intake between $C D$ and $P D$, nor between $P D$ and MD. Furthermore significantly lower carbohydrate intake occurred in the PD compared with the $C D$ and $M D(P<0.05)$. $C D$ and $M D$ did not differ significantly in terms of carbohydrate consumed. Significantly lower protein intake was associated with $C D$ compared with PD and MD ( $P<0.05)$, but no significant differences were noted between PD and MD. Finally, no significant differences were observed in fat and water intakes between the three dietary regimens.

\section{TABLE \|}

Daily nutrient intake of subjects on mixed, carbohydrate and protein diets $(n=6)$ (mean \pm S.E.)

\begin{tabular}{|c|c|c|c|c|c|}
\hline Dietary regimen & Mixed & Carbohyd & Irate & \multicolumn{2}{|c|}{ Protein } \\
\hline Carbohydrate (g) & $290.3 \pm 30.0$ & $298.0 \pm$ & 86.1 & $41.5 \pm$ & 18.5 \\
\hline Protein (g) & $81.4 \pm 9.9$ & $44.5 \pm$ & 5.5 & $161.3 \pm$ & 20.3 \\
\hline Fat (g) & $92.2 \pm 10.4$ & $60.3 \pm$ & 7.4 & $123.1 \pm$ & 54.0 \\
\hline Water (g) & $1123.4 \pm 151.8$ & $801.6 \pm$ & 93.1 & $754.4 \pm$ & 185.9 \\
\hline Energy (kj) & $9491.3 \pm 900.6$ & $7237.2 \pm 5$ & 528.3 & $7946.5 \pm 1$ & 1200.4 \\
\hline
\end{tabular}

* Significantly different at the 0.05 level

The physiological and biochemical responses and performance times during high intensity exercise following the three dietary treatments are presented in Table III. No significant differences were observed in heart rate, oxygen consumption or respiratory exchange ratio (R) following completion of exercise at a workload equivalent to $80 \%$ $\mathrm{VO}_{2}$ max continued to exhaustion. Furthermore no significant differences were noted in blood glucose concentration associated with high intensity exercise continued to exhaustion following the three dietary regimens. However, significantly lower blood lactate concentrations were

\section{TABLE III}

Time to exhaustion and cardiorespiratory responses immediately after exhausting high intensity exercise following three different dietary regimens $(n=6)$ (mean \pm S.E.)

\begin{tabular}{|c|c|c|c|c|}
\hline Heart rate & $\begin{array}{c}\text { Mixed } \\
\text { Mean } \pm \text { S.E. }\end{array}$ & \multicolumn{2}{|c|}{$\begin{array}{l}\text { Carbohydrate } \\
\text { Mean } \pm \text { S.E. }\end{array}$} & $\begin{array}{c}\text { Protein } \\
\text { Mean } \pm \text { S.E. }\end{array}$ \\
\hline (b.min-1) & $183.0 \pm 4.0$ & $182.0 \pm$ & 4.0 & $179.0 \pm 4.0$ \\
\hline $\mathrm{VO}_{2}\left(1 \cdot \min ^{-1}\right)$ & $3.06 \pm 0.47$ & $3.10 \pm$ & 0.55 & $2.88 \pm 0.53$ \\
\hline $\begin{array}{l}\% \mathrm{VO}_{2} \max \\
\mathrm{R} .\end{array}$ & $\begin{array}{rll}85.3 & \pm 0.2 \\
0.96 & \pm 0.01\end{array}$ & $\begin{array}{r}86.3 \pm \\
0.98 \pm\end{array}$ & $\begin{array}{l}0.2 \\
0.02\end{array}$ & $\begin{array}{rll}86.5 & \pm 0.2 \\
0.98 & \pm 0.03\end{array}$ \\
\hline Exercise time & $895.7 \pm 84.3$ & $1070.0 \pm$ & 06.7 & $642.5 \pm 88.3$ \\
\hline
\end{tabular}

* Significantly different at the 0.01 level

observed following PD compared with $M D$ and $C D(P<0.05)$. Moreover, a significantly greater exercise time to exhaustion was observed following $C D$ compared with MD and $P D(P<0.01)$. Exercise time following $M D$ and $P D$ did not differ significantly although there was a trend toward reduced performance times following the PD regimen.

\section{DISCUSSION}

It is recognised generally that the maintenance of prolonged high intensity exercise is partly dependent upon muscle glycogen content (Bergström et al, 1967; Gollnick et al, 1974) and that dietary and/or exercise depletion of glycogen stores inhibit the performance of such exercise (Costill and Miller, 1980). Furthermore elevation of muscle glycogen stores before exercise has been related to the accelerated use of glycogen in active muscle as well as enhanced carbohydrate oxidation rates (Sherman et al, 1981), therefore the importance of dietary sources is well established (Gollnick and Matoba, 1984).

The results of the present study suggest that endurance performance of cycle ergometry exercise at approximately $80 \% \mathrm{VO}_{2}$ max was influenced by the dietary regimen during the proceeding three days. In terms of endurance time to voluntary exhaustion, the $C D$ and $M D$ regimens resulted in approximately $40 \%$ and $28 \%$ improvement compared with the PD regimen, despite the fact that the PD and MD regimens provided somewhat higher energy intakes than the $C D$ regimen ( $9 \%$ and $24 \%$ respectively). However, total energy intakes were not significantly different between the $C D$ and $P D$ regimens (Table II) and there were no significant changes in $\mathrm{VO}_{2}$ max (Table I) over the experimental period ( 3 weeks). Moreover the energy demands of normal training were held constant. It is therefore suggested that the availability of specific energy sources may have contributed to the differences in performance observed. Furthermore, the total energy intake was significantly greater for the MD regimen than for the $C D$ regimen $(P<0.01$, Table II) and endurance times were approximately $16 \%$ lower in the MD regimen. Consequently it is suggested that glycogen stores may have been enhanced following the $C D$ regimen and this effect could have contributed to the increased performance times observed (Sherman et al, 1981). However blood glucose concentrations after $5 \mathrm{~min}$ and on termination as well as at $5 \mathrm{~min}$ post-exercise were not significantly different between trials although resting blood glucose levels were somewhat higher (NS) following the CD regimen than following the PD regimen (Table IV), suggesting that circulating carbohydrate was readily available for glycogen replenishment. 


\section{TABLE IV}

Blood glucose and blood lactate responses before, during and after high intensity exercise following mixed, carbohydrate and protein diets (mean \pm S.D.)

\begin{tabular}{|c|c|c|c|c|}
\hline & Pre trial & $\begin{array}{c}5 \mathrm{~min} \\
\text { exercise }\end{array}$ & $\begin{array}{l}\text { End } \\
\text { exercise }\end{array}$ & $\begin{array}{c}5 \text { min post } \\
\text { exercise }\end{array}$ \\
\hline \multicolumn{5}{|c|}{ Blood glucose (mmol. $1^{-1}$ ) } \\
\hline Mixed & $5.03 \pm 0.27$ & $4.53 \pm 0.22$ & $5.17 \pm 0.59$ & $5.83 \pm 0.60$ \\
\hline Protein & $4.55 \pm 0.23$ & $4.71 \pm 0.16$ & $5.10 \pm 0.45$ & $5.75 \pm 0.48$ \\
\hline Carbohydrate & $5.47 \pm 0.44$ & $4.65 \pm 0.18$ & $5.42 \pm 0.53$ & $5.83 \pm 0.70$ \\
\hline \multicolumn{5}{|c|}{ Blood lactate (mmol. $\mathrm{I}^{-1}$ ) } \\
\hline Mixed & $1.35 \pm 0.09$ & $5.98 \pm 0.77$ & $-8.73 \pm 0.81$ & $7.88 \pm 0.56$ \\
\hline $\begin{array}{l}\text { Protein } \\
\text { Carbohydrate }\end{array}$ & $\begin{array}{l}1.26 \pm 0.01 \\
1.38 \pm 0.09\end{array}$ & $\begin{array}{l}4.83 \pm 0.38 \\
5.60 \pm 0.40\end{array}$ & $\begin{array}{r}6.56 \pm 0.54 \\
8.42 \pm 0.43\end{array}$ & $\begin{array}{l}6.55 \pm 0.80 \\
7.22 \pm 0.67\end{array}$ \\
\hline
\end{tabular}

* Significantly different at the 0.05 level

Evidence to support the suggestion that provision of dietary carbohydrate may have influenced performance times can be found in the estimated contribution of carbohydrate to total energy intake (Table II), which revealed that the relative proportion of energy derived from carbohydrate sources associated with the three dietary regimens was $85 \%, 65 \%$ and $12 \%$ for CD, MD and PD respectively. Moreover, there was a moderate, positive relationship observed across the dietary regimens between total carbohydrate intake and endurance performance time $(r=0.59, P<0.05)$. These observations suggest that enhanced carbohydrate availability after the $C D$ regimen may have resulted in the preferential use of glycogen stores during high intensity exercise (Sherman et al, 1981) and point to the importance of dietary sources of carbohydrate in maintaining glycogen stores during the period leading up to exhaustive exercise (Gollnick and Matoba, 1984). The enhanced storage and use of glycogen could have contributed to significant improvements in exercise time to exhaustion associated with the $C D$ regimen.

Finally, blood lactate concentration tended to be lower before, during and after exercise following the PD than following the other dietary regimens. This difference was significant (Table IV) at exhaustion. The differences observed in blood lactate levels after exercise may have been partly a function of the increased duration of exercise associated with the $C D$ and MD regimens. Additionally, the differences in blood lactate concentration between the respective dietary regimens may reflect differences in muscle glycogen concentration (Jacobs, 1986). It is known that dietary carbohydrate influences the relative $\mathrm{VO}_{2}$ at which OBLA occurs (Yoshida, 1986) and that elevation of blood lactate concentration is associated with carbohydrate loading (Wilson and Cureton, 1984). It is likely that higher blood lactate concentrations observed during the high intensity exercise trials were related to the preceeding levels of dietary carbohydrate intake (Kelman et al, 1975). Furthermore the contribution of blood lactate to energy sources for muscular contraction via the lactate "shuttle" mechanism (Brooks, 1986) cannot be overlooked.

In conclusion, the findings of the present study suggest that the importance of the ratio of carbohydrate to total energy intake of the dietary regimen should not be overlooked in the nutritional preparation of athletes engaged in high intensity activity of less than $\mathbf{2 0}$ min duration.

\section{References}

Asstrand, P.-O. and Rodahl, K., 1986. Textbook of Work Physiology Physiological basis of exercise. McGraw Hill, New York.

British Association of Sports Sciences, 1986. Position statement on the physiological assessment of the elite athlete (Eds. T. Hale, A. Hardman, P. Jakeman, C. Sharp and E. Winter).

Brooks, G. A., 1986 "The 'lactate shuttle' during exercise: evidence and possible controls". Sports Science (Eds. J. Watkins, T. Reilly and L. Burwitz). E. and F. N. Spon, London pp. 69-82.

Bergström, J. L., Hermensen, L., Hultman, E. and Saltin, B., 1967 "Diet, muscle glycogen and physical performance". Acta Physiologica Scandinavica 70: 140-150.

Coyle, E. F. and Coggan, A. R., 1984 "Effectiveness of carbohydrate feeding in delaying fatigue during prolonged exercise". Sports Medicine 1: 446-458.

Costill, D. L. and Miller, J. M., 1980 "Nutrition for endurance sport Carbohydrate and fluid balance". International Journal of Sports Medicine 1: 2-14.

DHSS, 1969. Recommended intakes of nutrients for the UK. Report on Public Health and medical Subjects, 120, HMSO, London

Gollnick, P. D., Piehl, K. and Saltin, B., 1974 "Selective glycogen depletion pattern in human muscle fibers after exercise of varying intensity and at varying pedalling rates". Journal of Physiology (London) 1: 45-57.

Gollnick, P. D. and Matoba, H., 1984 "Role of carbohydrate in exercise" Clinics in Sports Medicine Vol. 3, No. 3: 583-593.

Jacobs, I., 1986 "Blood lactate - implications for training and sports performance". Sports Medicine 3: 10-25.

Jakeman, P. and Davies, B, 1979 "The characteristics of low resistance breathing valve designed for the measurement of high aerobic capacity". British Journal of Sports Medicine 13: 81-83.

Kelman, G. R., 1975 "The effect of dietary modifications on blood lactate during exercise". Journal of Physiology (London) 251: 34-35.

Lamb, D. R., 1984. The Physiology of Exercise - Responses and Adaptations. McMillan, New York.

McLaren, D. P. M. and Morgan, G. D., 1985 “Effects of sodium bicarbonate ingestion on maximal exercise". Proceedings of the Nutrition Society, 44 25A (Abstract).

Paul, A. and Southgate, D., 1979. McCance and Widdowson's - The Composition of Food, MRC Special Report 297, HMSO, London.

Sherman, W. M., Costill, D. L., Fink, W. J. and Miller, J. M., 1981 "Effect of exercise-diet manipulation on muscle glycogen and its subsequent utilisation during performance". International Journal of Sports Medicine 2: 114-118.

Wilson, G. E. and Cureton, K. J., 1984 "Effects of glycogen depletion and glycogen loading on anaerobic threshold and distance running performance". Medicine and Science in Sports and Exercise 16: 190-195.

Yoshida, T., 1986 "Effects of dietary modifications on anaerobic threshold". Sports Medicine 3: 3-9. 